\title{
Circulating MicroRNAs in Colorectal Cancer Huang $\mathbf{Q}^{1 *}$, Ge $\mathbf{B}^{1 *}$, Hu $\mathbf{M}^{1}$, Zhou $\mathbf{J}^{1}$ and Bai $\mathbf{X}^{2}$ \\ ${ }^{1}$ Department of General Surgery, Tongji Hospital, Tongji University School of Medicine, Shanghai-200065, P.R. China ${ }^{2}$ Department of Gynaecology, Shandong Zibo Central Hospital, Zibo 255036, P.R. China
}

\begin{abstract}
Colorectal cancer (CRC) poses a serious threat to the health of global populations. Screening for the early detection of CRC is important to improve patient survival. Circulating microRNAs (miRNAs, miRs), as nucleic acid markers, play variety of important roles in early screening, diagnosis, TNM stage and prognosis of CRC. In this review, an overview covers recent researches on the roles of circulating miRNAs and their variety potential values correlated with CRC. Studies on the detectable marker values of circulating miRNAs for CRC will help making a global consensus of procedures and standardized protocols to make their clinical transformation more reliable.
\end{abstract}

Keywords: Colorectal cancer; Biomarkers; Circulating MiRNAs

\section{Introduction}

With increasing incidence, colorectal cancer (CRC) remains the second most common cancer in women and the third in men, despite the improved screening techniques, most patients diagnosed CRC are at late stage, CRC is the second leading cause of cancer-related death worldwide [1]. Complete tumor resection by surgery is the main therapeutic modality, it was reported that 5 -year survival rates were in range from $93.2 \%$ for the earliest stage to $6.6 \%$ for advanced disease at diagnosis according to Duke's stage. So, good prognosis of CRC is linked to stage at earlier diagnosis. However, due to asymptomatic in early stage of CRC, many cases were detected at late stage. In clinical practice, colonoscopy is used in the diagnosis and treatment of CRC, but has not yet been wide-used as a screening tool because of some limitations, such as the requirements of bowel preparation, cost burden and perforation risk [2]. In addition, fecal occult blood test (FOBT), some convenient circulating blood biomarkers, including the most frequently used marker carcinoembryonic antigen (CEA), carbohydrate antigens, CA125, CA153 and CA199, are lack of sufficient sensitivity or specificity. For example, the specificity of FOBT is about $95 \%$, while the sensitivity of is around $70 \%$ to $75 \%$ [3], the sensitivity and specificity of CEA is $60 \%$ and $34 \%$, respectively [4]. Therefore, new strategies and novel biomarkers with the characters of detection, staging and prediction of outcome are highly desirable and being explored in order to make optimized treatment prescription and to improve prognosis for CRC patients.

A growing number of researches focus on small non-coding RNA molecules, microRNAs (miRNAs, miRs), which play multiple roles in variety of biological processes, including cancer [5-7]. Since 2008, tumor-derived miRNAs were described present stablely in circulating blood, as circulating-based markers for cancer detection [8]. Consider the detection of circulating miRNAs have the advantages of simple, inexpensive and noninvasive, combined with the remarkable stability characteristics of mature miRNAs due to the miRNA-Argonaute-protein complex, the discovery of circulating miRNAs as novel biomarkers for cancer intervention has been widely explored $[9,10]$. Growing evidences have indicated that aberrant expression of circulating miRNAs has an association with cancer including CRC. The diagnostic and prognostic value of circulating miRNAs exhibited in screening and monitoring, predicting recurrence or metastasis including lymph node, vessel, peritoneal invasion or distant metastasis, stratification by TNM stage or even histological differentiation grade, and few are associated with drug resistance, chemoradiosensitivity, tumor size and gender. This review covers recent researches in circulating miRNAs and their variety potential values correlated with CRC (Figure 1).

\section{Experiment Flow}

Experiment flow for the identification of CRC-related circulating miRNAs apply step-wise strategy. First experiment samples are selected according to different experimental purpose, microarraybased screening is used for expression profiling. Following is usually the training phase, after an extended scale validation by qRT-PCR, the results obtained from the screening phase are obtained. To the interesting results obtained from the training phase, $\mathrm{qRT}$-PCR is used for further validation, correlation analysis is explored for identifying and verifying target miRNAs relevant to CRC.

\section{Main circulating miRNAs in CRC diagnosis}

Early diagnosis and surgical intervention is the most effective treatment and benefit for prognosis improvement of CRC patients. Review of previous studies, we recruited 35 of 46 articles encompassed more than 45 circulating miRNAs, which can be used as biomarker for discriminating CRC patients from control subjects (Table 1). Most miRNAs, including let-7a, let-7g, miR-15b, miR-17, miR-18a, miR19a, miR-20a, miRNA-21, miR-23a, miR-24, miR-27a-3p, miR-29a, miR-106a, miR-125b, miR-133a, miR-139-3p, miR-141, miR-142-5p, miR-143, miR-152, miR-182, miR-193a-3p, miR-200c, miR-210, miR221, miR-223, miR-320a, miR-338-5p, miR-372, miR-376c-3p, miR378, miR-423-5p, miR-431, miR-1229, miR-1246 and miR-1290 were increased in plasma or serum source from CRC, while some miRNAs, including miR-26a-5p, miR-29b, miR-31, miR-142-3p, miR-181b, miR194, miR-195, miR-601 and miR-760 were decreased in circulating blood of CRC than healthy participants. Interestingly, few miRNAs, such as miR-34a, miR-92, miR-145, miR-150, miR-203, presented contradictory results in different studies.

In a study blood samples of 63 CRC patients and 45 controls were collected, expression of 7 target miRNAs was measured using qRT-PCR, the results showed that miR-34a was significantly reduced in CRC [11].

*Corresponding authors: Dr. Qi Huang and Dr. Bujun Ge, Department of General Surgery, Tongji Hospital, Tongji University School of Medicine, 389 Xin Cun Road Shanghai-200065, P.R. China, Tel: 00862166111428, Fax: 00862166111428; E-mail: hqhq007@hotmail.com, gebujun@126.com

Received June 16, 2017; Accepted July 06, 2017; Published July 10, 2017

Citation: Huang Q, Ge B, Hu M, Zhou J, Bai X (2017) Circulating MicroRNAs in Colorectal Cancer. J Mol Genet Med 11: 274 doi:10.4172/1747-0862.1000274

Copyright: @ 2017 Huang Q, et al . This is an open-access article distributed under the terms of the Creative Commons Attribution License, which permits unrestricted use, distribution, and reproduction in any medium, provided the original author and source are credited 


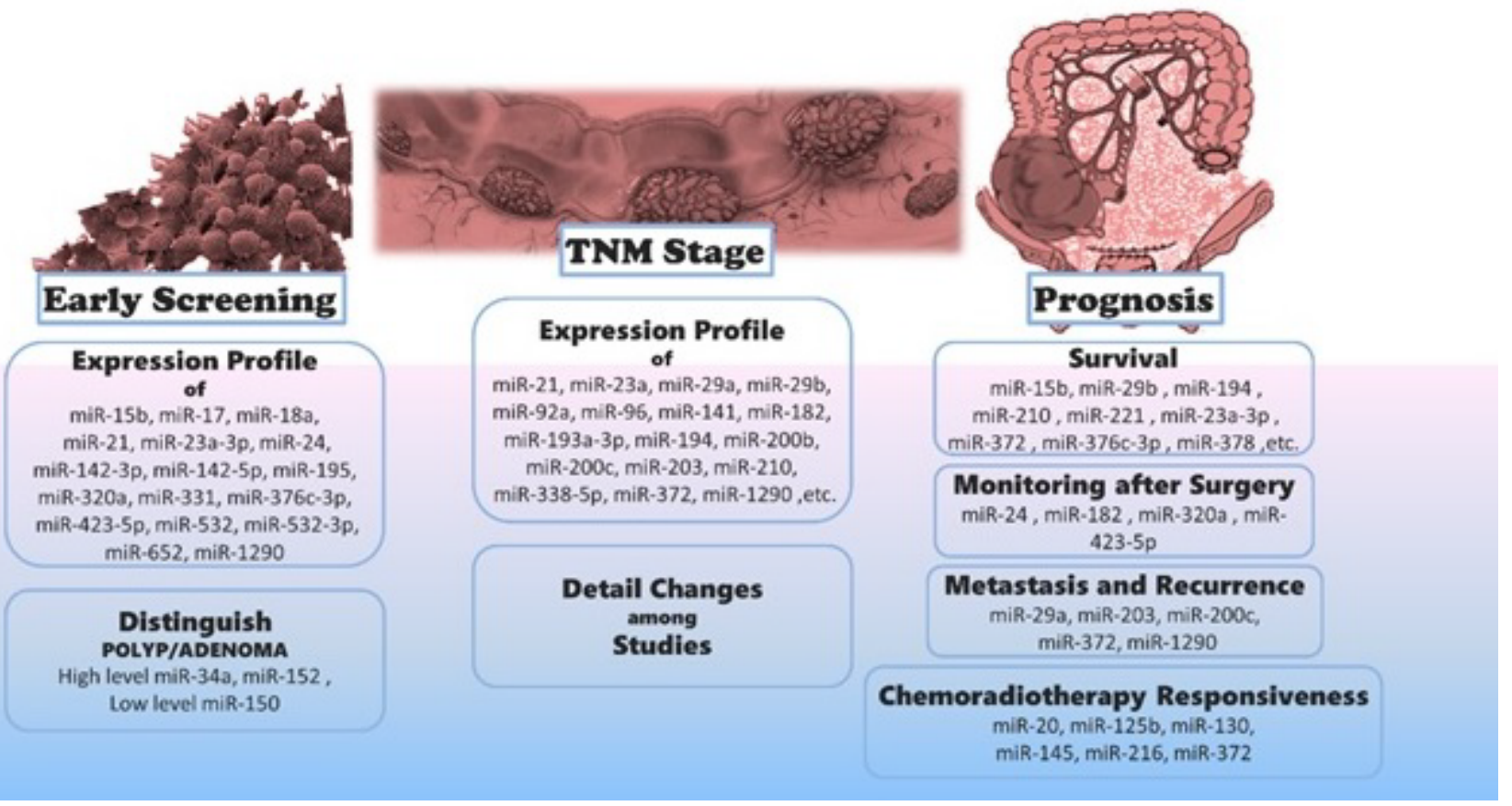

Figure 1: Circulating miRNAs and their variety potential values correlated with CRC.

\begin{tabular}{|c|c|c|c|c|c|c|c|c|}
\hline miRNAs & Sources & Relationship & Country & Group & Aim & Assay & Objective & References \\
\hline miR-203 & serum & + & Japan & 186 CRC, 24control & Prognosis & qRT-PCR & Human & {$[20]$} \\
\hline $\begin{array}{l}\text { miR-23a-3p, miR- } \\
27 a-3 p, \text { miR-142- } \\
5 p, \text { miR-376c-3p }\end{array}$ & serum & + & Czech & $\begin{array}{l}427 \text { colon cancer, } \\
276 \text { control }\end{array}$ & $\begin{array}{l}\text { Diagnosis and } \\
\text { Prognosis }\end{array}$ & $\begin{array}{c}\text { Sequencing, RT- } \\
\text { PCR }\end{array}$ & Human & [32] \\
\hline miR-1290 & serum & + & Japan & $\begin{array}{l}12 \text { stage IV CRC, } 12 \\
\text { adenoma, } 12 \text { control }\end{array}$ & Detection and Prognosis & microRNA array & Human & [25] \\
\hline miR-15b & plasma & + & China & 212 CRC, 156 control & Diagnosis and Prognosis & RT-PCR & Human & \\
\hline $\begin{array}{l}\text { miR-17, miR-19a, } \\
\text { miR-20a, miR-223 }\end{array}$ & serum & + & Egypt & $30 \mathrm{CRC}, 24$ control & Diagnosis & $\begin{array}{l}\text { miScript miRNA } \\
\text { PCR }\end{array}$ & Human & \\
\hline $\operatorname{miR}-125 b$ & serum & + & Italy & $34 \mathrm{CRC}$ & Biomarker & qRT-PCR & Human & \\
\hline $\begin{array}{l}\text { miR-96, miR-203, } \\
\text { miR-141, miR-200b }\end{array}$ & plasma & + & USA & $40 \mathrm{CRC}, 10$ control & Prognosis & TaqMan Array & Human & [54] \\
\hline miR-223, miR-92a & plasma & + & China & $62 \mathrm{CRC}, 62$ control & Detection & $\begin{array}{l}\text { multiplex qRT- } \\
\text { PCR }\end{array}$ & Human & [16] \\
\hline$m i R-194, m i R-29 b$ & serum & _- & Iran & $55 \mathrm{CRC}, 55$ control & Diagnosis and Prognosis & qRT-PCR & Huamn & \\
\hline miR-210 & serum & + & China & 268 CRC, 102 control & Diagnosis and Prognosis & qRT-PCR & Human & \\
\hline miR-21, miR-152 & plasma & + & Chicago & $\begin{array}{c}31 \text { CRC, } 33 \text { adenomatous } \\
\text { polyps, } 52 \text { control }\end{array}$ & Diagnosis & RT-PCR & Human & [34] \\
\hline $\begin{array}{l}\text { miR-29, miR-92, } \\
\text { miR-145, miR-195 }\end{array}$ & plasma &,+- & Saudi & $20 \mathrm{CRC}$ & Diagnosis & qRT-PCR & Human & [19] \\
\hline miR-372 & serum & + & China & 199 CRC/CPL, 30 control & Detection and Prognosis & qRT-PCR & Human & [24] \\
\hline ImiR-18b, miR-20a & plasma & + & Germany & 42 rectal cancer & $\begin{array}{c}\text { Chemoradiosensitivity Lymph } \\
\text { Node Status }\end{array}$ & qPCR & Human & \\
\hline miR-103, miR-720 & serum & + & Japan & $10 \mathrm{CRC}$ & TNM Stage & $\begin{array}{l}\text { Microarray qRT- } \\
\text { PCR }\end{array}$ & Human & \\
\hline $\begin{array}{l}\text { miR-21, miR-29a, } \\
\text { miR-125b }\end{array}$ & Serum & + & Japan & $160 \mathrm{CRC}, 77$ control & Diagnosis & RT-PCR & Human & \\
\hline $\begin{array}{l}\text { miR-24, miR-320a, } \\
\text { miR-423-5p }\end{array}$ & plasma & - & China & $\begin{array}{c}111 \text { cancer, } 59 \text { adenoma } \\
24 \text { polyps, } 29 \text { IBD, } 130 \\
\text { control }\end{array}$ & Diagnosis and Prognosis & qRT-PCR & Human & [29] \\
\hline miR-21 & serum & + & Australia & $\begin{array}{l}253 \text { adenomatous colon } \\
\text { polyps and control }\end{array}$ & Biomarker & PCR & Human & [28] \\
\hline miR-21-5p & plasma & + & Italy & $20 \mathrm{CRC}, 20$ control & Biomarker & $\begin{array}{l}\text { EvaGreen } \\
\text { ddPCR }\end{array}$ & Human & \\
\hline
\end{tabular}




\begin{tabular}{|c|c|c|c|c|c|c|c|c|}
\hline miR-106a, miR-20a & blood & + & China & 100 CRC, 79 control & Detection & qRT-PCR & Human & \\
\hline $\begin{array}{c}\text { miR-142-3p, miR- } \\
26 a-5 p\end{array}$ & plasma & - & Iran & $61 \mathrm{CRC}, 24$ control & Detection & qRT-PCR & Human & \\
\hline miR-34a, miR-150 & plasma &,+- & Czech & $\begin{array}{c}8 \text { normal, } 8 \text { polyp, } 16 \\
\text { adenoma, } 8 \text { stage I/III, } 8 \\
\text { stage III/IV }\end{array}$ & Diagnosis & RT-PCR & Human & [12] \\
\hline miR-199a-3p & serum & + & Japan & 10 paired CRC & TNM Stage & $\begin{array}{c}\text { microarray qRT- } \\
\text { PCR }\end{array}$ & Human & \\
\hline miR-21 & serum & + & Iran & $40 \mathrm{CRC}, 40$ control & Diagnosis and Prognosis & qRT-PCR & Human & [27] \\
\hline miR-182 & plasma & + & Italy & 51CRC, 10 control & Prognosis & qRT-PCR & Human & \\
\hline $\begin{array}{c}\text { let-7a, miR-1229, } \\
\text { miR-1246, miR- } \\
\text { 150, miR-21, miR- } \\
223, \text { miR-23a }\end{array}$ & $\begin{array}{l}\text { serum } \\
\text { exosome }\end{array}$ & + & Japan & $88 \mathrm{CRC}, 11$ control & Diagnosis & $\begin{array}{c}\text { microarray qRT- } \\
\text { PCR }\end{array}$ & Human & [46] \\
\hline miR-200c & Serum & + & Japan & $182 \mathrm{CRC}, 42$ control & Prognosis & qRT-PCR & Human & [56] \\
\hline $\begin{array}{c}\text { miR-21, let-7g, } \\
\text { miR-31, miR-92a, } \\
\text { miR-181b, miR-203 }\end{array}$ & Serum &,+- & China & $30 \mathrm{CRC}, 30$ control & Diagnosis & qRT-PCR & Human & [18] \\
\hline $\begin{array}{l}\text { miR-20, miR-130, } \\
\text { miR-145, miR-216, } \\
\text { miR-372 }\end{array}$ & serum & nonresponder+ & China & $\begin{array}{l}93 \text { responders, } 80 \\
\text { nonresponders }\end{array}$ & Chemosensitivity & $\begin{array}{c}\text { array and qRT- } \\
\text { PCR }\end{array}$ & Human & \\
\hline miR-378 & plasma & + & Italy & $46 \mathrm{CRC}, 70$ control & Prognosis & qRT-PCR & Human & \\
\hline miR-21 & serum & - & Spain & 102 CRC & Prognosis & qRT-PCR & Human & \\
\hline $\begin{array}{l}\text { miR-431, miR-15b, } \\
\text { miR-139-3p }\end{array}$ & plasma & + & USA & $\begin{array}{l}\text { 20CRC, } 12 \text { control, } 9 \\
\text { adenoma }\end{array}$ & Diagnosis & RT-PCR & Human & \\
\hline miR-92a & plasma & + & Japan & 13 tumor, 13 control & $\begin{array}{l}\text { Tumor } \\
\text { Growth }\end{array}$ & qRT-PCR & Mice & [13] \\
\hline miR-18a, miR-29a & serum & + & Spain & $30 \mathrm{CRC}, 26$ control & Diagnosis & qRT-PCR & Human & \\
\hline $\begin{array}{l}\text { miR-193a-3p, miR- } \\
\text { 23a, miR-338-5p }\end{array}$ & blood & + & Malaysia & $42 \mathrm{CRC}, 18$ control & Detection & $\begin{array}{c}\text { microarray RT- } \\
\text { PCR }\end{array}$ & Human & \\
\hline $\begin{array}{c}\text { miR-18a, }-20 a,- \\
21,-29 a,-92 a \\
-106 b,-133 a,-143 \\
145\end{array}$ & plasma & + & German & $50 \mathrm{CRC}, 50$ control & Detection and Diagnosis & $\begin{array}{l}\text { microRNA array } \\
\text { qRT-PCR }\end{array}$ & Human & [36] \\
\hline $\operatorname{miR}-29 a$ & serum & + & Czech & $100 \mathrm{CRC}, 30$ control & $\begin{array}{l}\text { Detection in } \\
\text { TNM Stage }\end{array}$ & qRT-PCR & Human & [52] \\
\hline miR-34a & blood & - & Ireland & $63 \mathrm{CRC}, 45$ control & Diagnosis & qRT-PCR & Human & [11] \\
\hline miR-21 & serum & + & China & 174 cancer, 39 control & Diagnosis & RT-PCR & Human & \\
\hline miR-21 & plasma & + & USA & 20 CRC, 20 control & Diagnosis & RT-PCR & Human & \\
\hline miR-601, miR-760 & plasma & - & China & $90 \mathrm{CRC}, 58$ control & Detection & qRT-PCR & Human & [56] \\
\hline miR-29a & serum & + & China & $\begin{array}{c}38 \text { metastasis, } 36 \\
\text { non-metastasis }\end{array}$ & Detection & RT-PCR & Human & \\
\hline miR-141 & plasma & + & China & 102 CRC & Diagnosis and Prognosis & qRT-PCR & Human & [42] \\
\hline miR-221 & plasma & + & China & $103 \mathrm{CRC}, 37$ control & Diagnosis and Prognosis & qRT-PCR & Human & \\
\hline miR-29a, miR-92a & plasma & + & China & $\begin{array}{c}120 \mathrm{CRC}, 37 \\
\text { adenoma, } 59 \text { control }\end{array}$ & Detection & qRT-PCR & Human & [17] \\
\hline miR-92 & plasma & + & China & 90CRC, 50control & Diagnosis & RT-PCR & Human & [41] \\
\hline
\end{tabular}

Table 1: Potential circulating microRNA biomarkers for CRC.

Meanwhile, the result of a step-wise study yield plasma samples showed miR-34a was significantly up-regulated in CRC [12]. Another miRNA appeared contradictory was miR-92. Based on circulating plasma of mice bearing human colon cancer xenografts, the level of miR-92a was significantly increased [13]. A three-phase (marker discovery; marker selection and validation; large-scale validation) study showed miR-92 is significantly elevated in plasma of patients with CRC [14]. In a study of developing a multi-marker blood based test for diagnosis of CRC, miR-92a was found to be upregulated in pools of plasma samples of CRC patients compared with neoplasm-free controls [15]. Based on 62 paired-plasma samples, using stepwise approach, miR-92a was found over-expressed in CRC and performed best as biomarkers for detecting CRC [16]. Expression of 12 miRNAs in plasma samples was measured using RT-PCR, and the result showed that miR-92a was upregulated in patients with advanced colorectal neoplasia than healthy controls [17]. In a two-phase case-control test designed to identify serum miRNAs as candidate biomarkers for CRC diagnosis, miR-92a was down-regulated in CRC than control samples [18]. The similar contradictory results were also observed in the circulating miRNAs miR-145, miR-150 and miR-203[19-22].

\section{Values of circulating miRNAs as diagnostic biomarkers}

The serum or plasma miRNA (single or panel) to detect CRC yielded an area under the receiver operating characteristic curve (ROC) (AUC) value of $0.67-1.00$, with a sensitivity of $47.5 \%$ to $100 \%$ and a specificity of $41 \%$ to $100 \%$, some of which was more sensitive than biomarkers used in clinic, such as serum CEA was reported previously had $60 \%$ sensitivity and $34 \%$ specificity, the population level use of noninvasive stool DNA tests and the FOBT recommend by guidelines had sensitivities vary from $60 \%$ to $95 \%$ [23]. CEA, CA125 and CA199 have been reported with the restriction of low specificity and sensitivity, data from à single center study showed that the AUC of serum miRNA for 
early CRC diagnosis was significantly higher than that of combined tumor markers (CEA, CA125 and CA199) (0.854 vs. 0.613) [24]. It was worth mentioning that serum miR-1290 could discriminate CRC patients from healthy control, yielded an AUC value of 1.00, sensitivity of $100 \%$, specificity of $100 \%$ [25]. In this study designed step by step, the expression of serum miR-1290 was examined in 12 CRC patients, 12 adenoma patients and 12 healthy control subjects in the training step. The results showed higher levels of serum miR-1290 in CRC patients than healthy controls and adenoma patients $(\mathrm{p}<0.0001$ and 0.0027 , respectively). ROC analyses showed that levels of serum miR-1290 could distinguish CRC patients from control subjects, with an AUC value of 1.00 , sensitivity of $100 \%$ and specificity of $100 \%$, furthermore, serum miR-1290 levels could effectively differentiate bewteen adenoma patients and control subjects, with an AUC value of 0.722 , sensitivity of $50.0 \%$, specificity of $100 \%$. As a robust biomarker, there was a significant association between serum miR-1290 and aggression and invasion of CRC, moreover, high serum miR-1290 expression in CRC was associated with worse prognosis, tumor size, vessel invasion, $\mathrm{T}$ Stage, lymph node metastasis, liver metastasis, peritoneal metastasis, distant metastasis, and Tumor-Nodes-Metastasis (TNM) stage.

\section{Circulating miRNAs in early screening}

The above miRNAs in circulating can distinguish between CRC and normal controls. It is widely accepted that CRC mainly develop from precancerous lesions, i.e., polyps and adenomas after many transition stages of malignancy. It has been reported that if CRC patients were diagnosed at an early stage, more benefit would get from curative surgery [26]. As a result, circulating miRNAs aim to screen for the detection of CRC should have an efficiency at delineating the earlier lesions. Combined the above miRNAs, a unique serum or plasma expression profile of miR-15b, miR-17, miR-18a, miR-21, miR-23a-3p, miR-24, miR-142-3p, miR-142-5p, miR-195, miR-320a, miR-331, miR376c-3p, miR-423-5p, miR-532, miR-532-3p, miR-652 and miR-1290 could distinguish benign colorectal polyp or adenoma lesions from healthy controls with good accuracy or high AUC values [27-33]. High levels of circulating miR-34a, miR-152 and low miR-150 levels were associated with the distinguish of patients with polyps or adenomas from those with CRC (AUC from 0.537 to 0.904) [34]. Distinguish the polyp or adenoma group from the normal group and the benign lesions group is important to improve patient survival and facilitate cancer prevention through the detection and removal of polyps or adenomas.

\section{Circulating miRNAs in TNM stage}

Currently, the TNM staging system is remain a useful tool for clinicians, which can be used to estimate tumor burden, guide curative surgical intervention and predict prognosis of patients. Many studies involved circulating miRNAs reported that there was an association between the aberrant expression profiles in circulating blood of CRC and TNM stage. In the previous studies involved in this review, more than 25 circulating miRNAs were reported had an association between clinical TNM stage (including separate analysis of depth of tumor invasion and lymph node status) of CRC and expression levels of circulating miRNAs. These miRNAs contained miR-15b, miR-18a, miR-18b, miR-20, miR-21, miR-23a, miR-29a, miR-29b, miR-92a, miR96, miR-139-3p, miR-141, miR-152, miR-181b, miR-182, 193a-3p, miR194, miR-200b, miR-200c, miR-203, miR-210, miR-338-5p, miR-372, miR-431, miR-601, miR-760 and miR-1290. However, the increasing or decreasing trend closely related with the advancement of cancer TNM I-IV stages existed in circulating miR-21, miR-23a, miR-29a, miR-29b, miR-92a, miR-96, miR-141, miR-182, 193a-3p, miR-194, miR-200b, miR-200c, miR-203, miR-210, miR-338-5p, miR-372 and miR-1290.
The others were associated with either depth of tumor invasion or lymph node status, or between a certain stage and normal.

In terms of the same miRNA, inconsistent results were observed in different studies, such as miR-18a, miR-21 and miR-29a. Expression levels of serum miR-18a and miR-29a were able to distinguish stage III CRC patients from controls in a set of 30 CRC patients and 26 healthy controls [35]. In a study of validation set recruited 224 plasma cases in total from 80 CRC samples and 144 neoplasm-free individuals, higher expression levels of miR-18a, miR-21 and miR-29a were observed in the plasma of CRC samples than in neoplasm-free subjects, but lack of any significant association between the miRNAs and tumor stage [36]. In a study recruited 40 colorectal adenocarcinoma patients and 40 control subjects, expression levels of serum miR-21 were measured using qRT-PCR assay, the results showed high expression level of serum miR-21 was associated with high clinical stages in the patients. Similar results were found in miR-29a in a study recruited 100 sera of patients with CRC and 30 sera of healthy donors [37]. Some miRNAs can distinguish TNM stage in CRC tissue samples, but failed in circulating miRNAs. Take miR-92a as an example, though miR-92a was previously reported to be correlate with TNM stage as to the relationship between the clinicopathologic characteristics and miR-92a expression, based on plasma from 90 patients with CRC, miR-92 levels of individual tumor stage had significant differences when compared to the controls, but it did not vary significantly across the stage in another study [38]. It has been reported that the 5-year survival rate range from $93.2 \%$ for stage I to $8.1 \%$ for stage IV. Consequently, a reliable treatment plan according to TNM stage may lead to vastly different clinical outcomes [39]. As a more convenient and accurate diagnostic tool, circulating miRNAs have the potential to positively link early diagnosis and treatment of CRC to higher patient survival rates.

\section{Circulating miRNAs related to prognosis}

The quality of life is closely related to prognosis of patients with CRC. Besides circulating miRNAs related to TNM staging system, which currently be used as a tool for predicting prognosis and survival. Several circulating miRNAs have been proposed and verified to be used as an important predictive parameter, through which can improve patients' quality of life by choosing the best combination of treatment modalities, such as surgery, radiation, and/or chemotherapy. Researches about circulating miRNAs independent of TNM stage related to prognosis may focus on predict postoperative survival, early recurrence and metastasis. Kaplan-Meier curve was used for overall survival, relapse free survival and disease free survival analysis according to the levels of circulating miRNAs, such as miR-15b, miR29b, miR-194, miR-210, miR-221, miR-23a-3p, miR-372, miR-376c-3p and miR-378, aberrant expression led to a worse survival. Based on the difference of preoperative and postoperative expression levels of circulating miRNAs, take miR-24, miR-182, miR-320a and miR-4235 as examples, circulating miRNAs will be provided with potential prognosis values for CRC progression monitoring after surgery. As important prognostic related factors, metastasis and recurrence are major cause of deaths in patients with CRC, based upon logistic regression analysis, Cox proportional hazards regression analyses and ROC analysis, miR-29a, miR-203, miR-200c, miR-372 and miR-1290 were reported as potential biomarkers. Moreover, the application of pre- and post-operative chemoradiotherapy was also factors influencing the prognosis of patients, circulating miR-20, miR-125b, miR-130, miR145, miR-216 and miR-372 had been reported to be used as predictive biomarker of the chemoradiotherapy responsiveness.

\section{Discussion}

It has been estimated that over 95\% CRC patients will benefit from 
radical operation to the cases diagnosed at early stage. Several early detection procedures by colonoscopy, barium enema, stool- and bloodbased tests have been widely used in clinic, due to the restriction of low specificity and sensitivity and invasive nature, the minimally invasive blood based test appears to be more attractive. Circulating miRNAs are stable owing to protection from endogenous ribonuclease, with the superiority characteristics of ease to detect, relative noninvasive and reliable, make these molecules potential to be candidates as biomarkers to reflect various states in CRC progression [40]. Numerous circulating miRNAs have been reported and being explored in identifying as screening, diagnostic and prognostic biomarkers for CRC, but few have moved into clinical translation and widely available in the clinic, before entering clinical arena, numerous obstacles need to be overcome [41].

It has been suggested that tumor-derived miRNAs can be present in circulation based on the variation of circulating miRNAs' expression level pre- and post-operation, reflect from the expression levels of circulating miRNAs down-regulated after surgical resection of primary tumors. However, the expression level of the same miRNA is not always inconsistent in tissues with that in circulating system. In a study of miR141 predicts prognosis as circulating biomarker, plasma level of miR-141 was significantly higher in CRC patients than in controls, but the results also showed that miR-141 level was not significantly higher in tumor specimens than in paired adjacent normal controls [42]. It has also been suggested that miRNAs are secreted from tumor-independent cells, such as immune and inflammatory cells, which occur coincidentally at primary lesions, or secreted into body fluids, including blood, urine, and so on, via be packaged into exosomes [43-46]. To the pathways of miRNAs into circulating system, several studies demonstrated that different potential ways, such as direct leakage passive from broken tumor cell, regulation of chemokines expression and function in tumor microenvironment, selective activation and secretion, similar to the release of cytokines and hormones, microvesicle-embedded secretion [47-50].

Limit the clinical application of circulating miRNAs is also reflected in the inconsistent results. Tracing it to the cause of these conflicting conclusions of circulating miRNAs in diagnosis, early screening, TNM stage and prognosis, may be attributed to the following factors: (1) genetic variations among different region, ethnic groups and different environmental and dietary factors, (2) difference of sample collection procedures or processing conditions, the source choice of plasma, serum or whole blood (3) uniform inclusion and exclusion criteria of subjects (i.e., early or late stages of cancers) to the same research purpose (diagnosis or TNM stage), (4) usage of pooled samples, (5) different internal controls including miR-16, RNU6B or cel-miR-39, and variety ways of data normalization and analysis in the quantification of RNA levels with qRT-PCR, (6) different miRNA expression levels between tissue and plasma, (7) sample size, screening method, and so on [51-56].

Another limitation with the use of circulating miRNAs as biomarkers is that they are not unique for CRC, but act as broadspectrum biomarker for many other cancers or non-oncological diseases, such as lung, gastric, ovarian, pancreatic cancers and ulcerative colitis. Therefore, an effective and special diagnostic method should be considered for the clinical application target CRC.

\section{Conclusion}

This review examines issues and advantages of afflicted circulating miRNAs as biomarkers for CRC. Highlight the clinical significance need a global consensus of procedures and standardized protocols to make their clinical transformation more reliable.

\section{References}

1. Torre LA, Bray F, Siegel RL, Ferlay J, Lortet-Tieulent J, et al. (2015) Global cancer statistics, 2012. CA Cancer J Clin 65: 87-108.

2. Gimeno-Garcia AZ, Hernandez-Alvarez-de-Buylla N, Nicolas-Perez D, Carrillo M, Hernandez G, et al. (2016) Colorectal cancer screening in the familial risk population: Is colonoscopy still the strategy of choice? Gastroenterol Hepatol 39: 352-360.

3. Whitlock EP, Lin JS, Liles E, Beil TL, Fu R (2008) Screening for colorectal cancer: A targeted, updated systematic review for the U.S. Preventive Services Task Force. Ann Intern Med 149: 638-658.

4. Pawa N, Arulampalam T, Norton JD (2011) Screening for colorectal cancer: established and emerging modalities. Nat Rev Gastroenterol Hepatol 8: 711-722.

5. Bartel DP (2004) MicroRNAs: Genomics, biogenesis, mechanism, and function. Cell 116: 281-297.

6. Ebert MS, Sharp PA (2012) Roles for microRNAs in conferring robustness to biological processes. Cell 149: 515-524.

7. Musilova K, Mraz M (2015) MicroRNAs in B-cell lymphomas: How a complex biology gets more complex. Leukemia 29: 1004-1017.

8. Mitchell PS, Parkin RK, Kroh EM, Fritz BR, Wyman SK, et al. (2008) Circulating microRNAs as stable blood-based markers for cancer detection. Proc Nat Acad Sci U S A 105: 10513-10518.

9. Arroyo JD, Chevillet JR, Kroh EM, Ruf IK, Pritchard CC, et al. (2011) Argonaute2 complexes carry a population of circulating microRNAs independent of vesicles in human plasma. Proc Natl Acad Sci U S A 108: 5003-5008.

10. Fesler A, Jiang J, Zhai H, Ju J (2014) Circulating microRNA testing for the early diagnosis and follow-up of colorectal cancer patients. Mol Diagn Ther 18: 303-308.

11. Nugent M, Miller N, Kerin MJ (2012) Circulating miR-34a levels are reduced in colorectal cancer. J Surg Oncol 106: 947-952.

12. Aherne ST, Madden SF, Hughes DJ, Pardini B, Naccarati A, et al. (2015) Circulating miRNAs miR-34a and miR-150 associated with colorectal cancer progression. BMC Cancer 15: 329.

13. Yamada N, Nakagawa Y, Tsujimura N, Kumazaki M, Noguchi S, et al. (2013) Role of Intracellular and Extracellular MicroRNA-92a in Colorectal Cancer. Transl Oncol 6: 482-492.

14. Ng EK, Chong WW, Jin H, Lam EK, Shin VY, et al. (2009) Differential expression of microRNAs in plasma of patients with colorectal cancer: A potential marker for colorectal cancer screening. Gut 58: 1375-1381.

15. Luo X, Stock C, Burwinkel B, Brenner H (2013) Identification and evaluation of plasma microRNAs for early detection of colorectal cancer. PLoS One 8: e62880.

16. Chang PY, Chen CC, Chang YS, Tsai WS, You JF, et al. (2016) MicroRNA-223 and microRNA-92a in stool and plasma samples act as complementary biomarkers to increase colorectal cancer detection. Oncotarget 7: 1066310675.

17. Huang Z, Huang D, Ni S, Peng Z, Sheng W, et al. (2010) Plasma microRNAs are promising novel biomarkers for early detection of colorectal cancer. Int $\mathrm{J}$ Cancer 127: 118-126.

18. Wang J, Huang SK, Zhao M, Yang M, Zhong JL, et al. (2014) Identification of a circulating microRNA signature for colorectal cancer detection. PLoS One 9 : e87451.

19. Al-Sheikh YA, Ghneim HK, Softa KI, Al-Jobran AA, Al-Obeed O, et al. (2016) Expression profiling of selected microRNA signatures in plasma and tissues of Saudi colorectal cancer patients by qPCR. Oncol Lett 11: 1406-1412.

20. Hur K, Toiyama Y, Okugawa Y, Ide S, Imaoka H, et al. (2017) Circulating microRNA-203 predicts prognosis and metastasis in human colorectal cancer. Gut 66: 654-665.

21. Ogata-Kawata H, Izumiya M, Kurioka D, Honma Y, Yamada Y, et al. (2014) Circulating exosomal microRNAs as biomarkers of colon cancer. PLoS One 9: e92921.

22. Zhang J, Zhang K, Bi M, Jiao X, Zhang D, et al. (2014) Circulating microRNA expressions in colorectal cancer as predictors of response to chemotherapy. Anticancer Drugs 25: 346-352. 
23. Imperiale TF, Ransohoff DF, Itzkowitz SH, Levin TR, Lavin P, et al. (2014) Multitarget stool DNA testing for colorectal-cancer screening. N Engl J Med 370: $1287-1297$

24. Yu J, Jin L, Jiang L, Gao L, Zhou J, et al. (2016) Serum miR-372 is a diagnostic and prognostic biomarker in patients with early colorectal cancer. Anticancer Agents Med Chem 16: 424-431.

25. Imaoka H, Toiyama Y, Fujikawa H, Hiro J, Saigusa S, et al. (2016) Circulating microRNA-1290 as a novel diagnostic and prognostic biomarker in human colorectal cancer. Ann Oncol 27: 1879-1886.

26. Gupta AK, Brenner DE, Turgeon DK (2008) Early detection of colon cancer: New tests on the horizon. Mol Diagn Ther 12: 77-85.

27. Basati G, Emami Razavi A, Abdi S, Mirzaei A (2014) Elevated level of microRNA-21 in the serum of patients with colorectal cancer. Med Oncol 31: 205.

28. Beckett EL, Martin C, Choi JH, King K, Niblett S, et al. (2015) Folate status, folate-related genes and serum miR-21 expression: Implications for miR-21 as a biomarker. BBA Clin 4: 45-51.

29. Fang Z, Tang J, Bai Y, Lin H, You H, et al. (2015) Plasma levels of microRNA-24, microRNA-320a, and microRNA-423-5p are potential biomarkers for colorectal carcinoma. J Exp Clin Cancer Res 34: 86.

30. Kanaan Z, Rai SN, Eichenberger MR, Roberts H, Keskey B, et al. (2012) Plasma miR-21: A potential diagnostic marker of colorectal cancer. Ann Surg 256: 544-551.

31. Toiyama Y, Takahashi M, Hur K, Nagasaka T, Tanaka K, et al. (2013) Serum miR-21 as a diagnostic and prognostic biomarker in colorectal cancer. J Natl Cancer Inst 105: 849-859.

32. Vychytilova-Faltejskova P, Radova L, Sachlova M, Kosarova Z, Slaba K, et al. (2016) Serum-based microRNA signatures in early diagnosis and prognosis prediction of colon cancer. Carcinogenesis 37: 941-950.

33. Zekri AR, Youssef AS, Lotfy MM, Gabr R, Ahmed OS, et al. (2016) Circulating Serum miRNAs as Diagnostic Markers for Colorectal Cancer. PLoS One 11: e0154130.

34. Chen H, Liu H, Zou H, Chen R, Dou Y, et al. (2016) Evaluation of plasma miR21 and miR-152 as diagnostic biomarkers for common types of human cancers. J Cancer 7: 490-499.

35. Luo X, Stock C, Burwinkel B, Brenner H (2013) Identification and evaluation of plasma microRNAs for early detection of colorectal cancer. PLoS One 8: e62880.

36. Wang LG, Gu J (2012) Serum microRNA-29a is a promising novel marker for early detection of colorectal liver metastasis. Cancer Epidemiol 36: e61-67.

37. Zhou T, Zhang G, Liu Z, Xia S, Tian H (2013) Overexpression of miR-92a correlates with tumor metastasis and poor prognosis in patients with colorectal cancer. Int J Colorectal Dis 28: 19-24.

38. O'Connell JB, Maggard MA, Ko CY (2004) Colon cancer survival rates with the new American Joint Committee on Cancer sixth edition staging. J Natl Cancer Inst 96: 1420-1425.

39. Schwarzenbach H, Nishida N, Calin GA, Pantel K (2014) Clinical relevance of circulating cell-free microRNAs in cancer. Nat Rev Clin Oncol 11: 145-156.
40. Keller A, Meese E (2016) Can circulating miRNAs live up to the promise of being minimal invasive biomarkers in clinical settings? Wiley Interdiscip Rev RNA 7: 148-156.

41. Cheng $H$, Zhang L, Cogdell DE, Zheng $H$, Schetter AJ, et al. (2011) Circulating plasma MiR-141 is a novel biomarker for metastatic colon cancer and predicts poor prognosis. PLoS One 6: e17745

42. Hosseini M, Khatamianfar S, Hassanian SM, Nedaeinia R, Shafiee M, et al (2016) Exosome-encapsulated microRNAs as potential circulating biomarkers in colon cancer. Curr Pharm Des.

43. Lasser C (2013) Identification and analysis of circulating exosomal microRNA in human body fluids. Methods Mol Biol 1024: 109-128.

44. Matsumura T, Sugimachi K, linuma $H$, Takahashi $Y$, Kurashige J, et al. (2015) Exosomal microRNA in serum is a novel biomarker of recurrence in human colorectal cancer. Br J Cancer 113: 275-281.

45. Ogata-Kawata H, Izumiya M, Kurioka D, Honma Y, Yamada Y, et al. (2014) Circulating exosomal microRNAs as biomarkers of colon cancer. PLoS One 9: e92921.

46. Heneghan HM, Miller N, Lowery AJ, Sweeney KJ, Newell J, et al. (2010) Circulating microRNAs as novel minimally invasive biomarkers for breast cancer. Ann Surg 251: 499-505.

47. Kanaan Z, Rai SN, Eichenberger MR, Roberts H, Keskey B, et al. (2012) Plasma miR-21: A potential diagnostic marker of colorectal cancer. Ann Surg 256: $544-551$

48. O'Connell JB, Maggard MA, Ko CY (2004) Colon cancer survival rates with the new American Joint Committee on Cancer sixth edition staging. J Natl Cancer Inst 96: 1420-1425.

49. Slack FJ, Weidhaas JB (2008) MicroRNA in cancer prognosis. N Engl J Med 359: 2720-2722

50. Yang L, Belaguli N, Berger DH (2009) MicroRNA and colorectal cancer. World J Surg 33: 638-646.

51. Cheng HH, Yi HS, Kim Y, Kroh EM, Chien JW, et al. (2013) Plasma processing conditions substantially influence circulating microRNA biomarker levels. PLoS One 8: e64795.

52. Faltejskova P, Bocanek O, Sachlova M, Svoboda M, Kiss I, et al. (2012) Circulating miR-17-3p, miR-29a, miR-92a and miR-135b in serum: Evidence against their usage as biomarkers in colorectal cancer. Cancer Biomark 12: 199-204.

53. Ferracin M, Lupini L, Salamon I, Saccenti E, Zanzi MV, et al. (2015) Absolute quantification of cell-free microRNAs in cancer patients. Oncotarget 6: 14545 14555.

54. Sun Y, Liu Y, Cogdell D, Calin GA, Sun B, et al. (2016) Examining plasma microRNA markers for colorectal cancer at different stages. Oncotarget 7 : 11434-11449.

55. Suryawanshi S, Vlad AM, Lin HM, Mantia-Smaldone G, Laskey R, et al. (2013) Plasma microRNAs as novel biomarkers for endometriosis and endometriosisassociated ovarian cancer. Clin Cancer Res 19: 1213-1224.

56. Wang Q, Huang Z, Ni S, Xiao X, Xu Q, et al. (2012) Plasma miR-601 and miR760 are novel biomarkers for the early detection of colorectal cancer. PLoS One 7: e44398. 